\title{
Pengaruh Promosi Jabatan Dan Lingkungan Kerja Non Fisik Terhadap Kepuasan Kerja Pegawai Negeri Sipil Dinas Koperasi Usaha Kecil Dan Menengah Provinsi Bali
}

\author{
I Putu Juli Heriana ${ }^{1}$ \\ I Made Suasti Puja ${ }^{2}$ \\ ${ }^{1,2}$ Fakultas Ekonomi Bisnis dan Pariwiwsata Universitas Hindu Indonesia \\ Email : juliheriana57@gmail.com
}

\begin{tabular}{|l|l|l|} 
Diterima: 8 Desember 2020 & Direvisi: 16 Desember 2020 & Disetujui:20 Desember 2020 \\
\hline
\end{tabular}

\section{ABSTRACT}

Organizational goals depend on human resources who perform well, one of the policies that can be taken to obtain employees who perform well is to pay attention to job satisfaction. The purpose of this study was to determine the effect of promotion and non-physical work environment parisally and simultaneously on job satisfaction of employees of the Office of Cooperatives Small and Medium Enterprises, Bali Province. This research was conducted at the Bali Province Small and Medium Enterprises Cooperative Office. Methods of data collection through observation, interviews, literature study and questionnaires. The sampling method was saturated sampling technique. The number of respondents in this study were 53 people. The data analysis technique used is multiple linear regression analysis techniques. The results showed that (1) job promotion has a positive and significant effect partially on job satisfaction, (2) the non-physical work environment has a positive and partially significant effect on job satisfaction, and (3) job promotion and non-physical work environment simultaneously have an effect. positive and significant on job satisfaction.

Keywords: job promotion, non-physical work environment and job satisfaction.

\begin{abstract}
ABSTRAK
Tujuan organisasi bergantung pada sumber daya manusia yang berkinerja baik, salah satu kebijakan yang dapat diambil untuk memperoleh pegawai yang berkinerja baik adalah dengan memperhatikan kepuasan kerjanya. Tujuan penelitian ini adalah untuk mengetahui pengaruh promosi jabatan dan lingkungan kerja non fisik secara parisal dan simultan terhadap kepuasan kerja pegawai Dinas Koperasi Usaha Kecil dan Menengah Provinsi Bali. Penelitian ini dilakukan di Dinas Koperasi Usaha Kecil dan Menengah Provinsi Bali. Metode pengumpulan data melalui observasi, wawancara, studi kepustakaan dan kuesioner. Metode penentuan sampel dengan teknik sampling jenuh. Jumlah responden pada penelitian ini adalah 53 orang. Teknik analisis data yang digunakan adalah teknik analisis regresi linier berganda. Hasil penelitian menunjukkan bahwa (1) promosi jabatan berpengaruh positif dan signifikan secara parsial terhadap kepuasan kerja, (2) lingkungan kerja non fisik berpengaruh positif dan signifikan secara parsial terhadap kepuasan kerja, dan (3) promosi jabatan dan lingkungan kerja non fisik secara simultan berpengaruh positif dan signifikan terhadap kepuasan kerja.
\end{abstract}

Kata kunci : promosi jabatan, lingkungan kerja non fisik dan kepuasan kerja.

PENDAHULUAN 
Salah satu faktor produksi yang merupakan aset terpenting yang mutlak harus dimiliki oleh organisasi adalah sumber daya manusia. Peranan SDM dalam organisasi adalah sangat menentukan hidup matinya organisasi karena tergantung pada manusianya. Dengan demikian semakin disadari bahwa di dalam suatu perusahaan, manusia merupakan unsur yang sangat penting untuk mencapai hasil yang diharapkan oleh organisasi. Mengingat kelangsungan hidup organisasi bergantung pada sumber daya manusia yang berkinerja baik, salah satu kebijakan yang dapat diambil untuk memperoleh pegawai yang berkinerja baik adalah dengan memperhatikan kepuasan kerjanya.

Kepuasan kerja merupakan sikap emosional yang menyenangkan dan mencintai pekerjaannya. Menurut Hasibuan (2007:202), sikap ini dicerminkan oleh moral kerja kedisiplinan dan prestasi kerja. Kepuasan kerja mengacu kepada sikap individu secara umum terhadap pekerjaannya. Robbins (2006:10), berpendapat pada seorang dengan tingkat kepuasan kerja yang tinggi mempunyai sikap positif terhadap pekerjaannya, sedangkan seseorang yang tidak puas dengan pekerjaannya mempunyai sikap negatif terhadap pekerjaannya. Menurut Hasibuan (2009:03), faktor-faktor yang mempengaruhi kepuasan kerja adalah balas jasa yang adil dan layak, penempatan yang sesuai dengan keahlian, berat atau ringannya pekerjaan, suasana dan lingkungan pekerjaan, peralatan penunjang terlaksananya pekerjaan, sikap pimpinan dalam kepemimpinannya, dan sikap pekerjaan yang monoton atau tidak.

Faktor yang memiliki hubungan dengan kepuasan kerja pegawai adalah promosi jabatan. Promosi jabatan adalah kegiatan pemindahan pegawai, dari satu jabatan ke jabatan lain yang lebih tinggi (Nitisemito, 2002:81). promosi jabatan itu sendiri sebenarnya mempunyai nilai, karena promosi jabatan adalah merupakan bukti pengakuan antara lain terhadap prestasinya (Nitisemito dalam Kadarisman, 2013:131). Hasil dari penelitian terdahulu dari Adi Indrawan (2018), menyatakan bahwa variabel kepemimpinan transformasional, variabel promosi jabatan dan variabel lingkungan kerja non fisik secara parsial maupun secara simultan memiliki pengaruh positif dan signifikan terhadap kepuasan kerja karyawan.

Lingkungan kerja non fisik juga merupakan faktor yang menentukan kepuasan kerja pegawai. Sedarmayanti (2011:26), lingkungan kerja non fisik dalam suatu organisasi sangat penting untuk diperhatikan oleh pimpinan organisasi, walaupun lingkungan kerja non fisik tidak berpengaruh secara langsung dalam organisasi tersebut, namun lingkungan kerja non fisik ini mempunyai pengaruh langsung kepada pegawai yang bekerja, sedangkan lingkungan kerja non fisik menurut Wursanto (2009:269), sebagai sesuatu yang menyangkut segi psikis dari 
lingkungan kerja. Paramita (2014) dalam penelitiannya memperoleh hasil bahwa kompensasi, lingkungan kerja non fisik, dan motivasi kerja masing-masing secara parsial memiliki pengaruh positif dan signifikan terhadap kepuasan kerja karyawan serta kompensasi, lingkungan kerja non fisik, serta motivasi kerja memiliki pengaruh positif dan signifikan terhadap kepuasan kerja karyawan.

Penelitian ini dilakukan pada Dinas Koperasi UKM Provinsi Bali yang beralamat di Jl. DI Panjaitan, Niti Mandala Renon, Denpasar Selatan, Bali. Berdasarkan pra observasi yang telah dilakukan sebelumnya pada Dinas Koperasi UKM Provinsi Bali terdapat beberapa permasalahan yang timbul karena ketidakpuasaan kerja pada pegawai adalah 1) Pekerjaan yang kurang menarik dan dianggap monoton bagi para pegawai sehingga ada perasaan bosan atau kurang puas dalam bekerja sehingga diperlukannya promosi jabatan, 2) Promosi jabatan di Dinas Koperasi UKM Provinsi Bali sudah berjalan dengan baik akan tetapi masih ada saja beberapa pegawai yang sudah bekerja selama kurang lebih dari 10tahun belum mendapatkan promosi jabatan. 3) Kurang kondusifnya situasi di dalam bekerja yang berkaitan dengan hubungan antara atasan, rekan kerja dan bawahan untuk bekerjasama dalam menyelesaikan pekerjaan. Hal-hal tersebut yang membuat kepuasan kerja pegawai terhadap Dinas Koperasi UKM Provinsi Bali menurun.

Tujuan Penelitian ini adalah (1) untuk mengetahui pengaruh promosi kerja secara parsial terhadap kepuasan kerja pegawai negeri sipil Dinas Koperasi Usaha Kecil dan Menengah Provinsi Bali, (2) untuk mengetahui pengaruh lingkungan kerja non fisik secara parsial terhadap kepuasan kerja pegawai negeri sipil Dinas Koperasi Usaha Kecil dan Menengah Provinsi Bali, dan (3) untuk mengetahui pengaruh promosi kerja dan lingkungan kerja non fisik secara simultan terhadap kepuasan kerja pegawai negeri sipil Dinas Koperasi Usaha Kecil dan Menengah Provinsi Bali.

\section{TELAAH LITERATUR DAN HIPOTESIS}

\section{Kepuasan Kerja}

Menurut Robbins \& Judge (2008:40), kepuasan kerja adalah suatu perasaan yang positif tentang pekerjaan seseorang yang merupakan hasil dari evaluasi karakteristiknya. Rini dkk. (2013), kepuasan kerja adalah suatu perasaan menyenangkan yang merupakan hasil dari persepsi individu dalam rangka menyelesaikan tugas atau memenuhi kebutuhannya untuk memperoleh nilai-nilai kerja yang penting bagi dirinya. Dole \& Schroeder (2006:93), menyatakan bahwa kepuasan kerja adalah perasaan dan reaksi individu terhadap lingkungan pekerjaannya. Waspodo dan Minadaniati (2012), kepuasan kerja merupakan suatu sikap dari pegawai yang 
menggambarkan sikap positif atau negatif dari pencapaian achievement pegawai dalam pekerjaanya.

\section{Promosi Jabatan}

Menurut Siagian (2013:169) yang dimaksud promosi jabatan adalah apabila seorang pegawai dipindahkan dari satu pekerjaan ke pekerjaan lain yang tanggung jawabnya lebih besar, tingkatannya dalam hierarki jabatan lebih tinggi dan penghasilannya pun lebih besar pula. Menurut Rivai (2009:211) promosi jabatan adalah apabila seorang pegawai dipindahkan dari satu pekerjaan ke pekerjaan lain yang lebih tinggi dalam pembayaran, tanggung jawab dan level. Sedangkan menurut Tohardi dikutip dari Flippo (2002:382) menjelaskan bahwa promosi jabatan adalah merupakan perubahan dari pekerjaan yang satu ke yang lainnya yang mempunyai syaratsyarat lebih baik dalam hal kedudukan dan tanggung jawab.

\section{Lingkungan Kerja Non Fisik}

Menurut Sedarmayanti (2009:26), Lingkungan kerja non fisik adalah semua keadaan yang terjadi yang berkaitan dengan hubungan kerja, baik hubungan dengan atasan maupun hubungan sesama rekan kerja, ataupun hubungan dengan bawahan. Sementara itu, Wursanto (2009), dapat dikatakan bahwa lingkungan kerja non fisik disebut juga lingkungan kerja psikis, yaitu keadaan di sekitar tempat kerja yang bersifat non fisik. Lingkungan kerja semacam ini tidak dapat ditangkap secara langsung dengan pancaindera manusia, namun dapat dirasakan keberadaannya.

\section{Hipotesis Penelitian}

1. Pengaruh Promosi Jabatan (X1) terhadap Kepuasan Kerja (Y)

Hasil penelitian yang dilakukan oleh Hilal Akbar (2017), dalam penelitiannya menunjukkan bahwa secara parsial promosi jabatan (X1) berpengaruh signifikan terhadap kepuasan kerja (Y), sedangkan mutasi jabatan (X2) tidak berpengaruh signifikan terhadap kepuasan kerja (Y). Junita Yanti Tambunan (2012) dalam penelitiannya menunjukkan bahwa secara simultan lingkungan kerja dan promosi jabatan berpengaruh secara signifikan terhadap kepuasan kerja pegawai. Secara parsial masing-masing faktor lingkungan kerja dan promosi jabatan berpengaruh signifikan terhadap kepuasan kerja pegawai.

H1: Diduga Promosi jabatan berpengaruh positif dan signifikan secara parsial terhadap kepuasan kerja pegawai negeri sipil Dinas Koperasi dan UKM Provinsi Bali.

2. Pengaruh Lingkungan Kerja Non Fisik (X1) terhadap Kepuasan Kerja (Y) 
Hasil penelitian yang dilakukan oleh Ni Nyoman Paramita Iswari Putri Pande (2014), dalam penelitiannya menunjukkan bahwa kompensasi, lingkungan kerja non fisik, dan motivasi kerja masing-masing secara parsial memiliki pengaruh positif dan signifikan terhadap kepuasan kerja karyawan serta kompensasi, lingkungan kerja non fisik, serta motivasi kerja memiliki pengaruh positif dan signifikan terhadap kepuasan kerja karyawan. Robby Alam Fath (2015), juga mengemukakan bahwa Lingkungan kerja non fisik berpengaruh positif terhadap kepuasan kerja karyawan hotel bintang dua di Yogyakarta, Karakteristik pekerjaan berpengaruh positif terhadap kepuasan kerja karyawan hotel bintang dua di Yogyakarta. Lingkungan kerja non fisik dan karakteristik pekerjaan secara simultan berpengaruh positif terhadap kepuasan kerja karyawan hotel bintang dua di Yogyakarta.

H2 : Diduga Lingkungan kerja non fisik berpengaruh positif dan signifikan secara parsial terhadap kepuasan kerja pegawai negeri sipil Dinas Koperasi dan UKM Provinsi Bali.

3. Pengaruh Promosi Jabatan (X1) dan Lingkungan Kerja Non Fisik (X2) terhadap Kepuasan Kerja (Y)

Hasil penelitian serupa oleh I Gede Adi Indrawan (2018) yang mendapatkan hasil bahwa variabel kepemimpinan transformasional, variabel promosi jabatan dan variabel lingkungan kerja non fisik secara parsial maupun secara simultan memiliki pengaruh positif dan signifikan terhadap kepuasan kerja karyawan PT Kustodian Sentral Efek Indonesia.

H3 : Diduga Promosi jabatan dan lingkungan kerja non fisik berpengaruh positif dan signifikan secara simultan terhadap kepuasan kerja pegawai negeri sipil Dinas Koperasi dan UKM Provinsi Bali.

\section{METODE PENELITIAN}

Desain penelitian ini menggunakan penelitian kuantitatif yang bersifat asosiatif dengan tujuan mengetahui pengaruh atau hubungan antara satu variabel atau lebih. Desain penelitian ini adalah pengaruh promosi jabatan dan lingkungan kerja non fisik terhadap kepuasan kerja pegawai pada Dinas Koperasi UKM Provinsi Bali. Populasi dalam penelitian ini adalah seluruh Pegawai Negeri Sipil Dinas Koperasi UKM Provinsi Bali yang berjumlah 53 orang. Teknik sampling yang digunakan adalah sampel jenuh, yaitu teknik penentuan sampel bila semua anggota populasi digunakan sebagai sampel. Pengumpulan data dilakukan dengan metode observasi, wawancara, studi kepustakaan, dan kusioner. Jawaban yang diberikan oleh para responden akan diukur masing-masing dengan menggunakan Skala Likert dengan lima pilihan jawaban yaitu jawaban sangat setuju diberi nilai 5, jawaban setuju diberi nilai 4, jawaban kurnag 
setuju diberi nilai 3, jawaban tidak setuju diberi nilai 2, dan jawaban sangat tidak setuu diberi nilai 1. Untuk menjawab hipotesis yangtelah diajukan, maka penelitian ini menggunakan teknik analisis data berupa analisis regresi linear berganda yaitu untuk menguji pengaruh variabel bebas promosi jabatan (X1) dan lingkungan kerja non fisik (X2) terhadap variabel terikat kepuasan $\operatorname{kerja}(\mathrm{Y})$

Gambar 1. Kerangka Berpikir

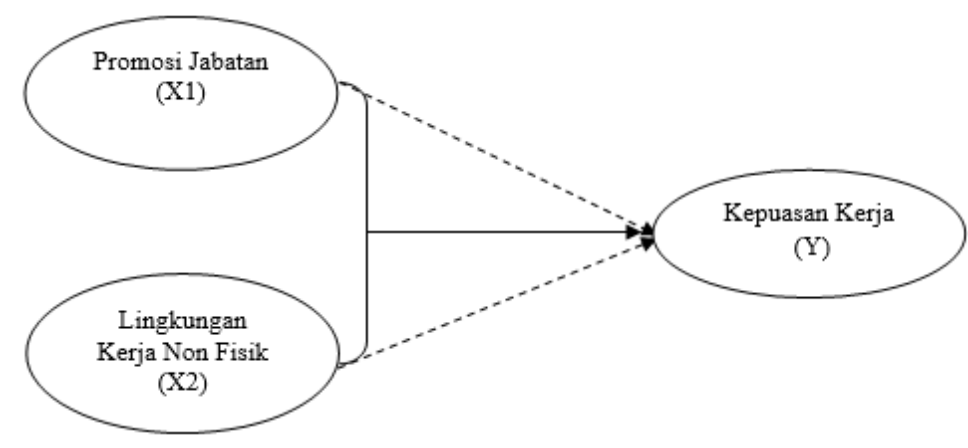

\section{HASIL DAN PEMBAHASAN}

\section{Uji Instrumen Penelitian}

Pada Tabel 1 didapat hasil bahwa seluruh butir instrumen dapat dinyatakan valid. karena seluruh koefisien korelasi lebih besar dibandingkan 0,30 dan memiliki koefisien Cronbach's Alpha lebih dari 0,60. Jadi dapat dinyatakan bahwa seluruh variabel telah memenuhi syarat reliabilitas atau kehandalan sehingga dapat digunakan untuk melakukan penelitian.

Tabel 1. Hasil uji Validitas dan Reliabilitas

\begin{tabular}{|c|c|c|c|c|c|}
\hline \multirow[b]{2}{*}{ Variabel } & \multirow[b]{2}{*}{$\begin{array}{c}\text { Item } \\
\text { pernyataan }\end{array}$} & \multicolumn{2}{|c|}{ Validitas } & \multicolumn{2}{|c|}{ Reliabilitas } \\
\hline & & $\begin{array}{c}\text { Koefisien } \\
\text { Korelasi } \\
\end{array}$ & Ket. & $\begin{array}{c}\text { Cronbach's } \\
\text { Alpha }\end{array}$ & Ket. \\
\hline \multirow{8}{*}{$\begin{array}{c}\text { Promosi } \\
\text { Jabatan }\end{array}$} & $\mathrm{X} 1.1$ & 0,858 & Valid & \multirow{8}{*}{0,939} & \multirow{8}{*}{ Reliabel } \\
\hline & $\mathrm{X} 1.2$ & 0,83 & Valid & & \\
\hline & $\mathrm{X} 1.3$ & 0,886 & Valid & & \\
\hline & $\mathrm{X} 1.4$ & 0,952 & Valid & & \\
\hline & $\mathrm{X} 1.5$ & 0,803 & Valid & & \\
\hline & X1.6 & 0,86 & Valid & & \\
\hline & $\mathrm{X} 1.7$ & 0,918 & Valid & & \\
\hline & $\mathrm{X} 1.8$ & 0,56 & Valid & & \\
\hline \multirow{4}{*}{$\begin{array}{c}\text { Lingkungan } \\
\text { Kerja Non } \\
\text { Fisik }\end{array}$} & $\mathrm{X} 2.1$ & 0,855 & Valid & \multirow{4}{*}{0,958} & \multirow{4}{*}{ Reliabel } \\
\hline & $\mathrm{X} 2.2$ & 0,825 & Valid & & \\
\hline & $\mathrm{X} 2.3$ & 0,943 & Valid & & \\
\hline & $\mathrm{X} 2.4$ & 0,904 & Valid & & \\
\hline
\end{tabular}




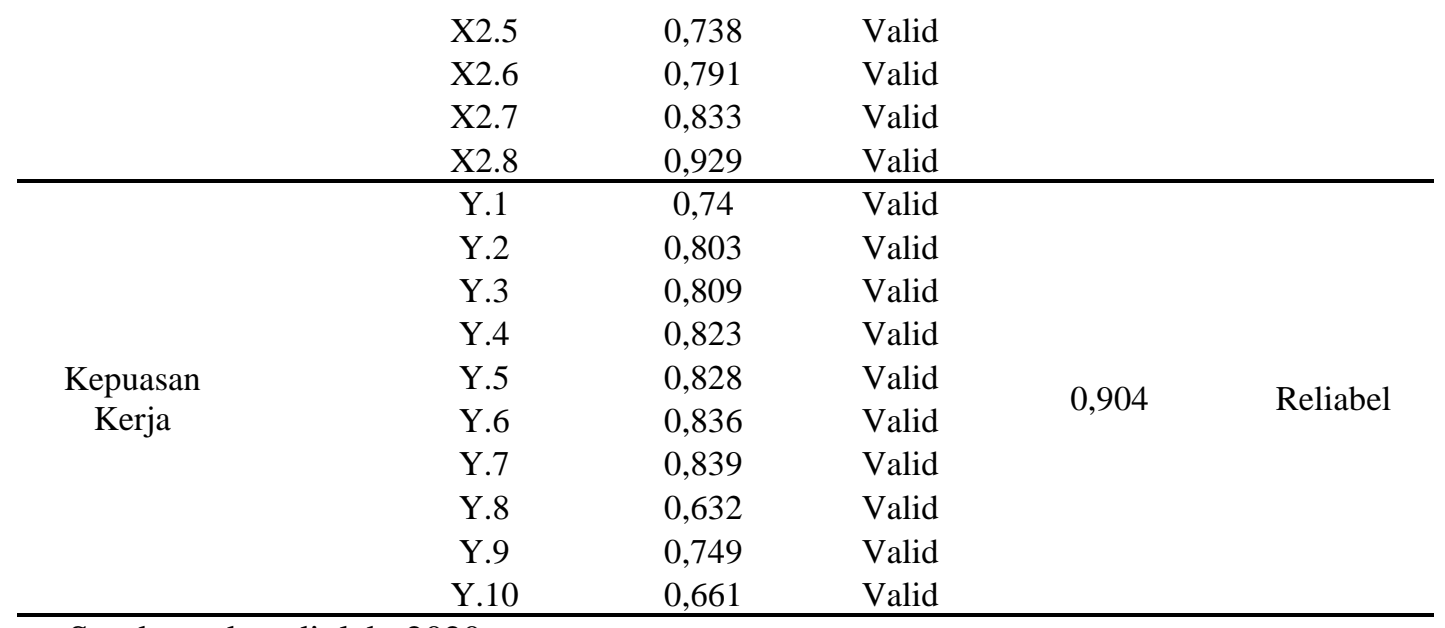

Sumber : data diolah, 2020

\section{Karakteristik Responden}

Dari hasil tabulasi data, maka dapat diketahui karakteristik responden dalam penelitian ini yang berjumlah sebanyak 53 orang responden berdasarkan kategori jenis kelamin, usia, pendidikan, dan masa kerja.

\section{Tabel 2. Karakteristik Frekuensi Responden}

\begin{tabular}{clcc}
\hline Kriteria & \multicolumn{1}{c}{ Pilihan } & Jumlah (Orang) & Persentase (\%) \\
\hline \multirow{4}{*}{ Jenis Kelamin } & 36 & 67,9 \\
& Laki-Laki & 17 & 32,1 \\
& Perempuan & 53 & 100 \\
& Jumlah & 12 & 22,6 \\
\multirow{5}{*}{ Usia } & $<25$ Tahun & 33 & 62,3 \\
& 25 - 40 Tahun & 8 & 15,1 \\
& $>40$ Tahun & 53 & 100 \\
\hline \multirow{5}{*}{ Pendidikan } & Jumlah & 15 & 28,3 \\
& SMA/Sederajat & 9 & 17 \\
& D1/D2/D3 & 29 & 54,7 \\
& D4/S1 & 53 & 100 \\
\hline \multirow{5}{*}{ Masa Kerja } & Jumlah & 23 & 43,4 \\
& $1-5$ Tahun & 24 & 45,3 \\
& 6-10 Tahun & 6 & 11,3 \\
& 11-15 Tahun & 53 & 100 \\
\hline
\end{tabular}

Sumber : data diolah, 2020

1. Responden dengan jenis kelamin pria sebanyak 36 orang dengan persentase 67,9\%. Sedangkan responden dengan jenis kelamin Perempuan sebanyak 17 orang dengan persentase $32,1 \%$. Hal ini menunjukkan responden dengan jenis kelamin pria lebih dominan dibandingkan perempuan.

2. Responden dengan usia $<25$ Tahun sebanyak 12 orang dengan persentase $22,6 \%$. Responden dengan usia 25 - 40 Tahun sebanyak 33 orang dengan persentase 62,3\%. Responden dengan usia lebih dari 40 Tahun sebanyak 8 orang dengan persentase $15,1 \%$. Hal ini menunjukkan responden dengan usia 25 - 40 Tahun yang paling mendominasi diantara usia lainnya. 
3. Responden dengan Pendidikan terakhir SMA/Sederajat sebanyak 15 orang dengan persentase 28,3\%. Responden dengan Pendidikan terakhir D1/D2/D3 sebanyak 9 orang dengan persentase 17,0\%. Responden dengan Pendidikan terakhir D4/S1 sebanyak 29 orang dengan persentase 54,7\%. Hal ini menunjukkan dari responden didominasi oleh Pendidikan terakhir $\mathrm{D} 4 / \mathrm{S} 1$.

4. Responden dengan masa kerja $1-5$ tahun sebanyak 23 orang dengan persentase $43,4 \%$. Responden dengan masa kerja 6 - 10 tahun sebanyak 24 orang dengan persentase 45,3\%. Responden dengan masa kerja 11 - 15 tahun sebanyak 6 orang dengan persentase $11,3 \%$. Hal ini menunjukkan dari responden didominasi dengan masa kerja 6 - 10 tahun.

\section{Uji Asumsi Klasik}

Berdasarkan Tabel 3 dapat dilihat bahwa nilai Kolmogorov Sminarnov (K-S) sebesar 0,116, sedangkan nilai Asymp, Sig, (2-tailed) sebesar 0,077. Hasil tersebut menunjukkan bahwa model persamaan regresi tersebut berdistribusi normal karena nilai Asymp, Sig, (2-tailed) lebih besar dari nilai alpha 0,05 .

\section{Tabel 3. Hasil Uji Normalitas}

One-Sample Kolmogorov-Smirnov Test

\begin{tabular}{llr}
\hline & & Unstandardized Residual \\
\hline $\mathrm{N}$ & Mean & 53 \\
Normal Parameters ${ }^{\mathrm{a}, \mathrm{b}}$ & Std. Deviation & 0 \\
& Absolute & 2,85717826 \\
Most Extreme Differences & Positive & 0,116 \\
& Negative & 0.085 \\
Test Statistic & & $-0,116$ \\
Asymp. Sig. (2-tailed) & & 0,116 \\
\hline
\end{tabular}

Sumber : data diolah, 2020

Berdasarkan Tabel 4 dapat dilihat bahwa nilai tolerance dan VIF dari variabel Promosi Jabatan dan Lingkungan Kerja Non Fisik menunjukkan nilai tolerance untuk setiap variabel lebih besar dari 0,10 dan nilai VIF lebih kecil dari 10 yang berarti tidak terjadi multikolenearitas.

\section{Tabel 4. Hasil Uji Multikolinearitas}

Coefficients $^{\mathbf{a}}$

\begin{tabular}{|c|c|c|c|}
\hline \multirow{2}{*}{ Model } & & \multicolumn{2}{|c|}{ Collinearity Statistics } \\
\hline & & Tolerance & VIF \\
\hline 1 & Promosi Jabatan & 0,778 & 1,286 \\
\hline 1 & Lingkungan Keria Non Fisik & 0,778 & 1,286 \\
\hline
\end{tabular}

a. Dependent Variable: Kepuasan Kerja

Sumber : data diolah, 2020 
Pada Tabel 5 dapat dilihat bahwa nilai signifikansi dari variabel Promosi Jabatan sebesar 0,296, nilai signifikan pada variabel Lingkungan Kerja Non Fisik sebesar 0,083. Nilai tersebut lebih besar dari 0,05 yang berarti tidak terjadi heterokedastitas.

Tabel 5. Hasil Uji Heteroskedastisitas

Sumber : data diolah, 2020

\begin{tabular}{rlrr}
\hline Model & & $\mathrm{t}$ & \multicolumn{1}{c}{ Sig. } \\
\hline \multirow{2}{*}{1} & (Constant) & 2,011 & 0,05 \\
& Promosi Jabatan & 1,055 & 0,296 \\
& Lingkungan Kerja Non Fisik & $-1,771$ & 0,083 \\
\hline
\end{tabular}

\section{Hasil Analisis Regresi Linier Berganda}

Teknik analisis data yang digunakan dalam penelitian ini adalah teknik regresi linear berganda. Pengujian regresi linear berganda digunakan untuk menguji variabel bebas yaitu promosi jabatan dan lingkungan kerja non fisik dengan kepuasan kerja sebagai variabel terikat.

Tabel 6. Hasil Analisis Regresi Linear Berganda

\begin{tabular}{|c|c|c|c|c|c|c|}
\hline \multirow{2}{*}{\multicolumn{2}{|c|}{ Model }} & \multicolumn{2}{|c|}{$\begin{array}{c}\text { Unstandardized } \\
\text { Coefficients }\end{array}$} & \multirow{2}{*}{$\begin{array}{c}\text { Standardized } \\
\text { Coefficients } \\
\text { Beta }\end{array}$} & \multirow[t]{2}{*}{$\mathrm{t}$} & \multirow[t]{2}{*}{ Sig. } \\
\hline & & $\mathrm{B}$ & Std. Error & & & \\
\hline \multirow{3}{*}{1} & (Constant) & 12,732 & 3,587 & & 3,549 & 001 \\
\hline & Promosi Jabatan &, 578 &, 101 & ,602 & 5,707 &, 000 \\
\hline & Lingkungan Kerja Non Fisik &, 273 &, 115 & ,250 & 2,365 &, 022 \\
\hline \multicolumn{2}{|r|}{ 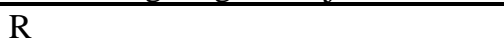 } & & & & & ,753 \\
\hline \multicolumn{2}{|c|}{$R$ Square } & & & & &, 567 \\
\hline \multicolumn{2}{|c|}{ Adjusted $R$ Square } & & & & &, 549 \\
\hline \multicolumn{2}{|c|}{ F hitung } & & & & & 32,708 \\
\hline \multicolumn{2}{|c|}{ Sig. } & & & & &, 000 \\
\hline
\end{tabular}

Sumber : data diolah, 2020

Berdasarkan Tabel 6 dapat diketahui persamaan regresinya :

$\mathrm{Y}=\alpha+\beta 1 . \mathrm{X} 1+\beta 2 . \mathrm{X} 2$

Dari hasil analisis regresi seperti yang disajikan pada Tabel 4.12, maka dapat dibuat persamaan struktural sebagai berikut: $\mathrm{Y}=12,732+0,578 \mathrm{X}_{1}+0,273 \mathrm{X}_{2}$.

Berdasarkan persamaan regresi linier berganda tersebut dapat dijelaskan koefisien-koefisiennya sebagai berikut:

a. Nilai konstanta diasumsikan bahwa tanpa ditambahkan variabel Promosi Jabatan dan Lingkungan Kerja Non Fisik maka nilai Kepuasan Kerja bernilai sebesar 12,732.

b. Apabila $\mathrm{X}_{1}$ (Promosi Jabatan) mengalami peningkatan sebesar 1 satuan dengan asumsi Lingkungan Kerja Fisik dianggap tetap maka Kepuasan Kerja akan meningkat sebesar 0,578, sehingga dapat dikatakan bahwa promosi jabatan berpengaruh positif terhadap kepuasan kerja. 
c. Apabila $\mathrm{X}_{2}$ (Lingkungan Kerja non Fisik) mengalami peningkatan sebesar 1 satuan dengan asumsi Promosi Jabatan dianggap tetap maka Kepuasan Kerja akan menurun sebesar 0,273, sehingga dapat dikatakan bahwa lingkungan kerja non fisik berpengaruh secara positif terhadap kepuasan kerja.

\section{Hasil Analisis Koefisien Determinasi}

Besarnya pengaruh variabel bebas terhadap variabel terikat yang ditunjukkan oleh nilai determinasi total (Adjused $R$ Square) sebesar 0,549 mempunyai arti bahwa sebesar 54,9\% variabel Kepuasan Kerja dipengaruhi oleh variabel Promosi Jabatan dan Lingkungan Kerja Non Fisik, sedangkan sisanya $(100 \%-54,9 \%=55,1 \%)$ dijelaskan oleh faktor lain yang tidak dimasukkan ke dalam model.

\section{Tabel 7. Uji Koefisiem Determinasi}

Model Summary ${ }^{b}$

\begin{tabular}{ccccc}
\hline Model & $\mathrm{R}$ & $\mathrm{R}$ Square & Adjusted R Square & $\begin{array}{c}\text { Std. Error of the } \\
\text { Estimate }\end{array}$ \\
\hline 1 & $0,753^{\mathrm{a}}$ & 0,567 & 0,549 & 2,914 \\
\hline
\end{tabular}

Sumber : data diolah, 2020

\section{Hasil Uji Pengaruh Parsial (Uji T)}

Uji statistik t pada dasarnya menunjukkan pengaruh satu variabel bebas secara individual dalam menerangkan variabel terikat. Uji T dilakukan untuk menguji Hipotesis 1 (H1) dan hipotesis 2 (H2) yang menyatakan bahwa masing-masing variabel promosi jabatan (X1) dan lingkungan kerja non fisik (X2) secara parsial berpengaruh positif dan signifikan terhadap kepuasan kerja (Y). Hasil Uji T dapat dilihat pada Tabel 6.

1. Pengaruh Promosi Jabatan Terhadap Kepuasan Kerja

Berdasarkan hasil analisis data didapat bahwa nilai signifikansi sebesar 0,000 kurang dari 0,05 maka Ho ditolak dan $\mathrm{H}_{1}$ diterima, dengan nilai koefisien regresi sebesar 0,578, Hasil ini mempunyai arti bahwa Promosi Jabatan berpengaruh positif dan signifikan terhadap Kepuasan Kerja pada Dinas Koperasi UKM Provinsi Bali.

Promosi Jabatan berpengaruh positif dan signifikan terhadap Kepuasan Kerja pada Dinas Koperasi UKM Provinsi Bali. Hal tersebut berarti setiap peningkatan Promosi Jabatan maka akan terjadi peningkatan Kepuasan Kerja pada Dinas Koperasi UKM Provinsi Bali.

Pemaparan di atas mendukung hasil penelitian yang dilakukan oleh Hilal Akbar (2017) yang membuktikan promosi jabatan berpengaruh signifikan terhadap kepuasan kerja. Junita Yanti Tambunan (2012) dalam penelitiannya menunjukkan bahwa secara simultan lingkungan kerja dan promosi jabatan berpengaruh secara signifikan terhadap kepuasan kerja pegawai. 
Secara parsial masing-masing faktor lingkungan kerja dan promosi jabatan berpengaruh signifikan terhadap kepuasan kerja pegawai.

2. Pengaruh Lingkungan Kerja Non Fisik Terhadap Kepuasan Kerja

Berdasarkan hasil analisis data didapat bahwa nilai signifikansi sebesar 0,022 kurang dari 0,05 maka Ho ditolak dan $\mathrm{H}_{2}$ diterima, dengan nilai koefisien regresi sebesar 0,273, Hasil ini mempunyai arti bahwa Lingkungan Kerja Non Fisik berpengaruh positif dan signifikan terhadap Kepuasan Kerja pada Dinas Koperasi UKM Provinsi Bali.

Lingkungan Kerja Non Fisik berpengaruh positif dan signifikan terhadap Kepuasan Kerja pada Dinas Koperasi UKM Provinsi Bali. Hal tersebut berarti setiap peningkatan Lingkungan Kerja Non Fisik maka akan terjadi penurunan Kepuasan Kerja pada Dinas Koperasi UKM Provinsi Bali.

Pemaparan di atas mendukung hasil penelitian yang dilakukan oleh Ni Nyoman Paramita Iswari Putri Pande (2014) yang telah membuktikan lingkungan kerja non fisik memberikan pengaruh positif dan signifikan terhadap kepuasan kerja dan bersama-sama dengan motivasi dan kompensasi juga bmemberikan pengaruh positif dan signifikan terhadap kepuasan kerja. Robby Alam Fath (2015), juga telah membuktikan lingkungan kerja non fisik berpengaruh positif dan signifikan terhadap kepuasan kerja, dan lingkungan fisik bersama-sama dengan karakteristik pekerjaan berpengaruh positif dan signifikan terhadap kepuasan kerja.

\section{Uji Signifikansi Simultan (Uji F)}

Uji statistik $\mathrm{F}$ bertujuan untuk melihat apakah semua variabel independen yang dimasukkan dalam model mempunyai pengaruh secara bersama-sama terhadap variabel dependen.

\section{Tabel 7. Hasil Uji F}

\begin{tabular}{|c|c|c|c|c|c|c|}
\hline \multicolumn{7}{|c|}{ ANOVA $^{a}$} \\
\hline Mode & & $\begin{array}{c}\text { Sum of } \\
\text { Squares }\end{array}$ & df & $\begin{array}{c}\text { Mean } \\
\text { Square }\end{array}$ & $\mathrm{F}$ & Sig. \\
\hline \multirow{3}{*}{1} & Regression & 1.182 .228 & 2 & 591.114 & 73.867 & $.000^{\mathrm{b}}$ \\
\hline & Residual & 760.231 & 95 & 8.002 & & \\
\hline & Total & 1.942 .459 & 97 & & & \\
\hline
\end{tabular}

Sumber : data diolah, 2020

Berdasarkan hasil analisis data diperoleh nilai $\mathrm{F}_{\text {hitung }}>\mathrm{F}_{\text {tabel, }}$ 32,708 $>$ 3,18 dengan nilai sig, 0,000 < 0,05, maka Ho ditolak dan $\mathrm{H}_{3}$ diterima, Hal ini menunjukan bahwa ada pengaruh yang positif dan signifikan secara simultan antara Promosi Jabatan dan Lingkungan Kerja Non Fisik secara bersama terhadap Kepuasan Kerja pada Dinas Koperasi UKM Provinsi Bali. Promosi Jabatan dan Lingkungan Kerja Non Fisik secara bersama-sama berpengaruh positif dan 
signifikan terhadap Kepuasan Kerja pada Dinas Koperasi UKM Provinsi Bali. Hal tersebut berarti setiap peningkatan Promosi Jabatan dan Lingkungan Kerja Non Fisik secara bersamaan maka akan terjadi peningkatan Kepuasan Kerja pada Dinas Koperasi UKM Provinsi Bali.

Hasil penelitian ini mendukung hasil penelitian yang dilakukan I Gede Adi Indrawan (2018) yang membuktikan bahwa variabel promosi jabatan dan variabel lingkungan kerja non fisik berpengaruh positif dan signifikan terhadap kepuasan kerja karyawan PT Kustodian Sentral Efek Indonesia baik secara parsial maupun simultan.

\section{PENUTUP}

\section{Simpulan}

1. Ada pengaruh positif dan signifikan antara Promosi Jabatan terhadap Kepuasan Kerja pada Dinas Koperasi UKM Provinsi Bali, yang artinya semakin tinggi Promosi Jabatan yang diberikan, maka akan terjadi peningkatan Kepuasan Kerja pada Dinas Koperasi UKM Provinsi Bali.

2. Ada pengaruh positif dan signifikan antara Lingkungan Kerja Non Fisik terhadap Kepuasan Kerja pada Dinas Koperasi UKM Provinsi Bali, yang artinya semakin baik Lingkungan Kerja Non Fisik, maka akan terjadi peningkatan Kepuasan Kerja pada Dinas Koperasi UKM Provinsi Bali. 1,676 dan nilai signifikan 0,022 sehingga hipotesis diterima.

3. Ada pengaruh positif dan signifikan antara Promosi Jabatan dan Lingkungan Kerja Non Fisik secara simultan terhadap Kepuasan Kerja pada Dinas Koperasi UKM Provinsi Bali. Hal tersebut berarti setiap peningkatan antara Promosi Jabatan dan Lingkungan Kerja Non Fisik secara bersama-sama akan meningkatkan pula Kepuasan Kerja pada Dinas Koperasi UKM Provinsi Bali.

\section{Saran}

1. Dinas Koperasi UKM Provinsi Bali hendaknya meningkatkan kualitas Kepuasan Kerja pegawai, dengan cara meningkatkan frekuensi Promosi Jabatan, hal tersebut dapat dilakukan dengan memberi perhatian lebih kepada pegawai yang berpengalaman dan berkompeten dalam pekerjaannya untuk dipromosikan jabatannya.

2. Dinas Koperasi UKM Provinsi Bali hendaknya meningkatkan kualitas Kepuasan Kerja pegawai, dengan cara memperhatikan Lingkungan Kerja Non Fisik, hal tersebut dapat dilakukan dengan memberikan kesempatan kepada seluruh pegawai untuk memperlihatkan kemampuan yang dimilikinya dengan cara memberi kesempatan untuk mengkuti pelatihanpelatihan kerja. 
3. Dinas Koperasi UKM Provinsi Bali hendaknya meningkatkan Kepuasan Kerja, hal tersebut dapat dilakukan dengan merancang regulasi secara simultan yang dapat mengoptimalkan Promosi Jabatan serta memperhatikan Lingkungan Kerja Non Fisik para pegawainya.

4. Bagi peneliti selanjutnya, agar dapat meneliti dan mengkaji lebih lanjut dengan menggunakan variabel-variabel lain yang kiranya dapat mempengaruhi Kepuasan Kerja selain Promosi Jabatan dan Lingkungan Kerja Non Fisik. Agar nantinya dapat mengetahui apa yang harus dilakukan Dinas Koperasi Usaha, Kecil dan Menengah Provinsi Bali untuk meningkatkan kepuasan kerja yang terjadi pada Dinas Koperasi Usaha, Kecil dan Menengah Provinsi Bali.

\section{REFERENSI}

Adi Indrawan, I Gede (2018). Analisis Pengaruh Kepemimpinan Transformasional, Promosi Jabatan, Lingkungan Kerja Non Fisik Terhadap Kepuasan Kerja Karyawan PT Kustodian Sentral Efek Indonesia. Jurnal Mandiri: Ilmu Pengetahuan, Seni, dan Teknologi. Vol. 2. No. 2.

Ardana, I Komang, Ni Wayan Mujiati, Anak Agung Ayu Sriathi. 2009. Perilaku Keorganisasian. Edisi Kedua. Yogyakarta: Graha Ilmu.

Aziri, B. 2011. Job Satisfication: A Literature Review. Management Research and Practice Vol 3, 77-86.

Bambang Wahyudi. (2010). Manajemen Sumber Daya Manusia. Jakarta: Sulita.

Cekmecelioglu, Hulya Gundus, Ayse Gunsel and Ulutas, Tugce. 2012. Effect of Emotional Intelligence on Job Satisfaction: An Empiral Study on Call Center Employees. ProcediaSocial and Behavior Science. 58. pp: 363-369.

Dole, Carol and Schroeder, Richard G. 2006. The Impact of Varios Factors on the Personality, Job Satisfaction and Turn Over Intention of Profesional Accountants, Managerial Auditing Journal, Vol. 16 No.4 pp 234-245

Edwin B. Flippo, 2002. Personel Management (Manajemen Personalia), Edisi. VII Jilid II, Terjemahan Alponso S, Erlangga, Jakarta.

Fathoni, Abdurrahmat. 2006. Manajemen Pernosalia dan Sumber Daya Manusia. Edisi keenam. Jakarta : Erlangga.

Ghozali, Imam. 2011. Aplikasi analisis Multivariate dengan Program IBM SPSS 19 (edisi kelima.) Semarang: Universitas Diponegoro.

Hasibuan, Malayu SP. 2005. Manajemen Sumber Daya Manusia, Edisi Revisi.

Hasibuan, Malayu SP. 2007. Manajemen, Edisi Revisi. PT. Bumi Aksara, Jakarta.

Hasibuan, Malayu S.P. 2009. Manajemen: Dasar, Pengertian dan Masalah Edisi Revisi. Jakarta: Bumi Aksara.

Hasibuan, Malayu S.P 2012. Manajemen Sumber Daya Manusia, Jakarta: Bumi Aksara. 
Hilal Akbar. (2017). Pengaruh Promosi Dan Mutasi Jabatan Terhadap Kepuasan Kerja Karyawan Pada PT. Jasa Marga (Persero) Tbk Cabang Belmera.

Junita Yanti Tambunan. (2012). Pengaruh Lingkungan Kerja dan Promosi Jabtan Terhadap Kepuasan Kerja Pegawai Bagian Umum Sekretariat Daerah Kabupaten Tapanuli Tengah.

Mutiara S, Panggabean. (2002). Manajemen Sumber Daya Manusia. Jakarta: Ghalia Indonesia.

Luthans, Fred. 2010 Perilaku Organisasi, (Alih Bahasa V.A Yuwono, dkk), Edisi Bahasa Indonesia, Yogyakarta: ANDI.

Naqvi, S.M.M.R., Ishtiaq, M., Kanwal, Nousheen., dan Ali, Moshin. 2013. Impact of job autonomy on organizational commitment and job satisfaction: the moderating role of organizational culture in fast food sector of Pakistan. International journal of business and management, 8(17): 92-102.

Nata Wirawan, I Gusti Putu. 2002. "Cara Mudah Memahami Statistik 2 (Statistik Inferensia) untuk ekonomi dan bisnis”. Denpasar. edisi kedua. Keraras Emas.

Nitisemito, Alex S. 2008. Manajemen Personalia (Manajemen Sumber Daya Manusia, Edisi Kelima, Cetakan Keempat belas, Ghalia Indonesia, Jakarta.

Nitisemito, Alex S. 2012. Manajemen Suatu Dasar dan Pengantar, Arena Ilmu, Jakarta.

Paramita Iswari Putri Pande, Ni Nyoman 2014. Pengaruh Kompensasi, Lingkungan Kerja Non Fisik, dan Motivasi Kerja Terhadap Kepuasan Kerja Karyawan World Brand Factory (WBF). E-Jurnal Manajemen. Vol.3. No.7

Permendargi nomor 54. 2010

Restra Dinas Koperasi Usaha Kecil dan Menengah Provinsi Bali. 2014

Rini, Dyah., Rusdarti., Suparjo. 2013. Pengaruh Komitmen Organisasi, Kepuasan Kerja dan Budaya Organisasi terhadap Organizational Citizenship Behavior: Studi pada PT. Plasa Simpanglima Semarang. Jurnal Ilmiah Dinamika Ekonomi dan Bisnis, 1 (1), pp: 212-219.

Rivai, Veithzal. \&pp Sagala, E.J. 2009. Manajemen Sumber Daya Manusia untuk Perusahaan. Raja Grafindo Persada, Jakarta.

Robby Alam Fath. 2015. Pengaruh Lingkungan Kerja Non Fisik Dan Karakteristik Pekerjaan Terhadap Kepuasan Kerja (Studi Pada Karyawan Hotel Bintang Dua Di Yogyakarta).

Robbins, Stephen, 2006, Perilaku Organisasi, Prentice Hall, edisi kesepuluh Sabardini, 2006, Peningkatan Kinerja Melalui Perilaku Kerja Berdasarkan Kecerdasan Emosional, Telaah Bisnis, Vol.7, No.1.

Robbins, Stephen P. \& Timothy A. Judge. (2008). Perilaku Organisasi Edisi ke-12, Jakarta: Salemba Empat.

Santjaka, A. 2011. Statistik untuk Penelitian Kesehatan. Yogyakarta: Nuha Medika.

Sedarmayanti. 2009. Tata Kerja dan Produktivitas Kerja. Bandung: CV Mandar Maju.

Sedarmayanti. 2011. Manajemen Perkantoran Modern. Bandung: Mandar Maju.

Sekaran, \& Bougie. (2013). Edisi 5, Research Methods for Business: A skill Building Approach.

New York: John wiley@Sons.

Siagian, Sondang P. (2013). Manajemen Sumber Daya Manusia, Edisi Pertama, Cetakan Keduapuluh Satu, Jakarta: Bumi Aksara.

Sugiyono. 2010. Metode Penelitian Bisnis. Bandung: Alfabeta. . 2012. Metode Penelitian Bisnis. Bandung: Alfabeta. 
Sugiyono. (2013). Metode Penelitian Pendidikan Pendekatan Kuantitatif, Kualitatif, dan R\&D. Bandung: Alfabeta. . (2014). Metode Penelitian Pendidikan Pendekatan Kuantitatif, Kualitatif, dan R\&D. Bandung: Alfabeta.

Sukardi. 2011. Metodologi Penelitian Pendidikan: Kompensasi dan Praktiknya. Cetakan kesepuluh. Jakarta: PT. Bumi Aksara.

Taskina, Ali. 2009. Job Satisfaction of Faculty Members in Private Universities-In Context of Bangladesh. International Business Research, 2(4).

Utama, Made Suyana, 2009, Statistika Ekonomi dan Bisnis, Penerbit : Udayana University Press, Denpasar.

Waspodo, Agung AWS. Dan Lussy Minadaniati. 2012. Kepuasan kerja dan Iklim Organisasi Terhadap Organizational Citizenship Behavior (OCB) Karyawan Pada PT. Trubus Swadaya Depok. Jurnal Riset Manajemen Sains Indonesia (JRMSI), 3 (1); pp: 1-16.

Wursanto, I., 2009. Dasar-Dasar Ilmu Organisasi, edisi dua. Yogyakarta: Andi. 